\title{
Coordinated Eph-ephrin signaling guides migration and axon targeting in the avian auditory system
}

\author{
Michelle R Allen-Sharpley and Karina S Cramer
}

\begin{abstract}
Background: In the avian sound localization circuit, nucleus magnocellularis (NM) projects bilaterally to nucleus laminaris (NL), with ipsilateral and contralateral NM axon branches directed to dorsal and ventral NL dendrites, respectively. We previously showed that the Eph receptor EphB2 is expressed in NL neuropil and NM axons during development. Here we tested whether EphB2 contributes to NM-NL circuit formation.

Results: We found that misexpression of EphB2 in embryonic NM precursors significantly increased the number of axon targeting errors from NM to contralateral NL in a cell-autonomous manner when forward signaling was impaired. We also tested the effects of inhibiting forward signaling of different Eph receptor subclasses by injecting soluble unclustered Fc-fusion proteins at stages when NM axons are approaching their NL target. Again we found an increase in axon targeting errors compared to controls when forward signaling was impaired, an effect that was significantly increased when both Eph receptor subclasses were inhibited together. In addition to axon targeting errors, we also observed morphological abnormalities of the auditory nuclei when EphB2 forward signaling was increased by E2 transfection, and when Eph-ephrin forward signaling was inhibited by E6-E8 injection of Eph receptor fusion proteins.
\end{abstract}

Conclusions: These data suggest that EphB signaling has distinct functions in axon guidance and morphogenesis. The results provide evidence that multiple Eph receptors work synergistically in the formation of precise auditory circuitry.

Keywords: Development, Brainstem, Auditory system, Axon guidance, Migration, Chick, Eph receptor

\section{Background}

The sensory epithelium of the auditory system is unique in that it contains an orderly representation of stimulus frequency that lacks information about auditory space. Our ability to localize sound sources relies on interaural time differences (ITDs) and interaural level differences (ILDs) encoded in auditory brainstem circuitry. Circuitry that detects ITDs is well characterized in the avian auditory brainstem (Figure 1), in which nucleus magnocellularis (NM) receives tonotopically arranged auditory afferents from the VIIIth nerve [1,2]. Each NM cell projects bilaterally to nucleus laminaris (NL), which contains neurons that have bitufted dendrites [3] and act as

\footnotetext{
* Correspondence: cramerk@uci.edu

Department of Neurobiology and Behavior, University of California Irvine,
} Irvine, CA 92697-4550, USA coincidence detectors that respond maximally when simultaneous input is received on both dorsal and ventral dendrites [4]. While axosomatic contacts are made on both sides, ipsilateral NM axon branches contact dorsal NL dendrites, whereas contralateral NM axon branches contact ventral NL dendrites [5-7]. The contralateral branches of $\mathrm{NM}$ axons terminate in delay lines in $\mathrm{NL}$ [8-10], so that the location of NL neurons receiving coincident bilateral input is correlated with the azimuth of the sound source $[8,11,12]$.

During development, contralaterally projecting NM axons cross the midline at E4 [13] and reach their target between E6 and E8 [14], at the same time that auditory brainstem nuclei begin to separate from the auditory anlage $[14,15]$. By E8, ipsilateral $\mathrm{NM}$ axon branches are visible. Synaptic connections from NM to NL form by E10, and axonal and synaptic refinement follow over the 

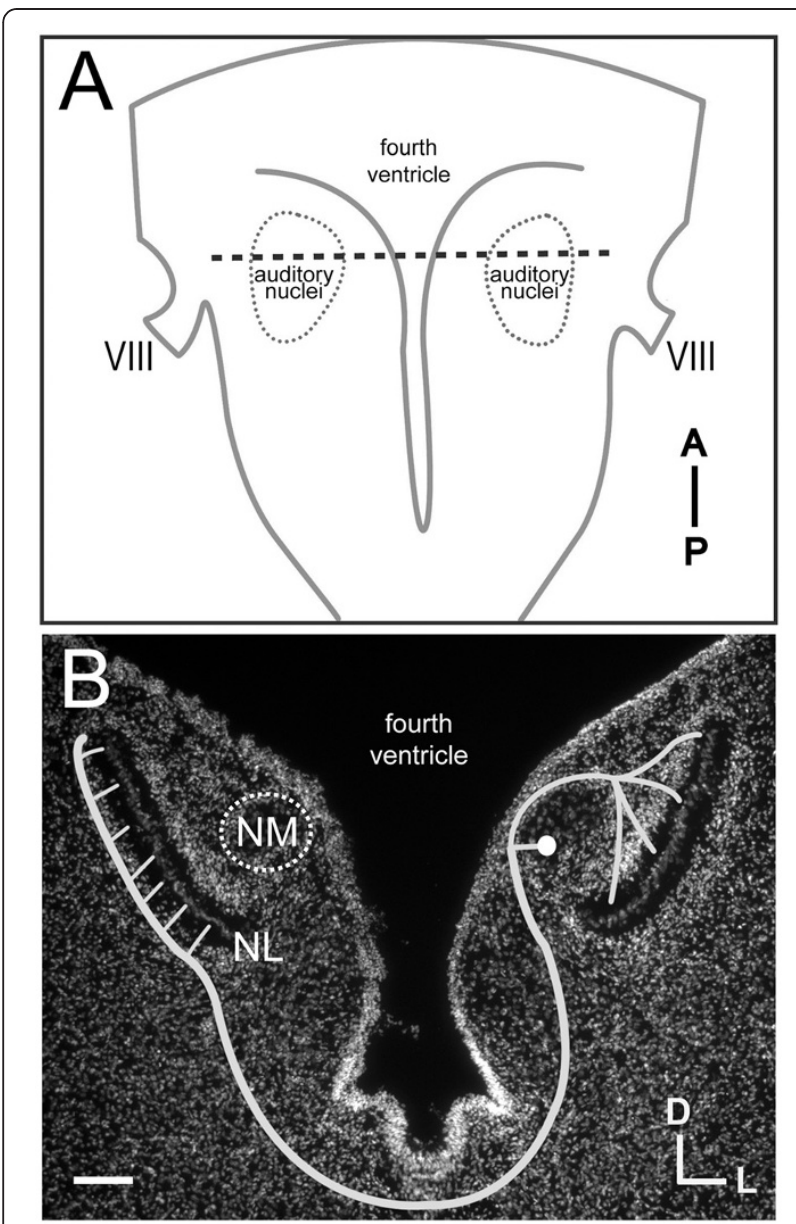

Figure 1 Schematized NM-NL circuit. (A) Illustration of a dissected chick embryo brainstem at E10 with auditory nuclei (including NM and $\mathrm{NL}$ ) outlined bilaterally and the coronal plane of section for (B) indicated with a dashed line. (B) Coronal section of an E10 chick auditory brainstem with bisbenzimide nuclear staining. Bilateral projections from a single representative right-sided NM cell are schematized. Ipsilateral NM axon contacts dorsal NL neuropil with divergent branches of similar length, while contralateral NM axon contacts ventral NL neuropil with a delay line. Note the absence of cells in the neuropil surrounding NL cells where NM axons synapse. Scale bar $=0.5 \mathrm{~mm}$ in (A) and $100 \mu \mathrm{m}$ in (B). VIII = eighth cranial (vestibulocochlear) nerve.

next several days $[7,15,16]$. Axons projecting from NM to $\mathrm{NL}$ are able to discriminate between the ventral versus dorsal dendrites of target cells with very few, if any, errors $[11,17,18]$. We have previously reported that Eph-ephrin signaling, known to be important for axon guidance and cell migration in other systems [19-25] has several distinct roles in the establishment of the NM-NL circuit [26-28].

Eph receptors comprise the largest class of receptor tyrosine kinases, and along with their ephrin ligands, are categorized into A and B subclasses based on structural similarity and binding affinities [29,30]. In general, EphA receptors bind ephrin-A ligands, and EphB receptors bind ephrin-B ligands, with two exceptions in which EphA4 also binds ephrin-B ligands [29,31] and EphB2 also binds ephrin-A5 [32]. Both receptor and ligand are membrane bound, with cell-cell interactions resulting in bidirectional signaling $[33,34]$ and either attractive or repulsive cues to axons or migrating cells. The cell bearing the Eph receptor undergoes "forward" signaling, while the cell bearing the ephrin undergoes "reverse" signaling [35]. Embryos with impaired Eph-ephrin signaling exhibit a range of auditory defects including altered cochlear innervation and function [36,37], abnormal axon targeting in the auditory brainstem [17,38-41] and significantly impaired hearing $[42,43]$.

At E10, when NM-NL contacts form, EphA4 is highly expressed in the dorsal, but not ventral, neuropil of NL [44]. In our previous study, we found that EphA4 misexpression resulted in a significant number of dorsoventral targeting errors from NM to contralateral NL [17]. However, the majority of NM axons terminated in their appropriate target region, suggesting that proper targeting relies on the coordinated functions of several molecules during development. We previously showed that several other Eph family proteins are expressed in NM and NL at the time that projections form [27]. Notably, EphB2 is expressed in both the dorsal and ventral NL neuropil, as well as in NM axons. In this study we tested whether EphB2 acts to segregate NM axons to appropriate dendritic regions of NL. We misexpressed EphB2 in NM cells using plasmid transfection or injected soluble Eph fusion proteins to inhibit forward signaling through Eph receptors in the region of NM axon growth, then examined the effects on the NM-NL pathway. We found that altering Eph-ephrin forward signaling during development of the NM-NL circuit resulted in impaired axon targeting, and that both EphA and EphB classes play a role in segregation of binaural inputs. Additionally, our studies suggest that EphB signaling is needed for the morphologic maturation of these auditory nuclei at several stages of embryonic development.

\section{Results}

\section{Transfection is limited to auditory nuclei and extensive} in NM cells

As we have previously shown $[17,45]$, transfection of auditory cell precursors by in ovo electroporation at E2 leads to prolonged plasmid expression as shown by EGFP reporter expression and by immunolabeling of protein encoded by the transfected plasmid. Transfection was directed focally to the auditory brainstem precursors at E2 by placing the electrodes at the level of r5 [46]. At E2, NM and NL cells are undergoing their final mitotic divisions and rhombomere boundaries are visible. Following electroporation at E2, inspection of embryos revealed normal rhombomere morphology at 
E3. EGFP was visible and limited to the auditory region of whole brainstems dissected at E10 (Figure 2A). We found extensive transfection throughout NM that included cell bodies and axons, with more limited transfection seen in NL. In cases with NL cell transfection

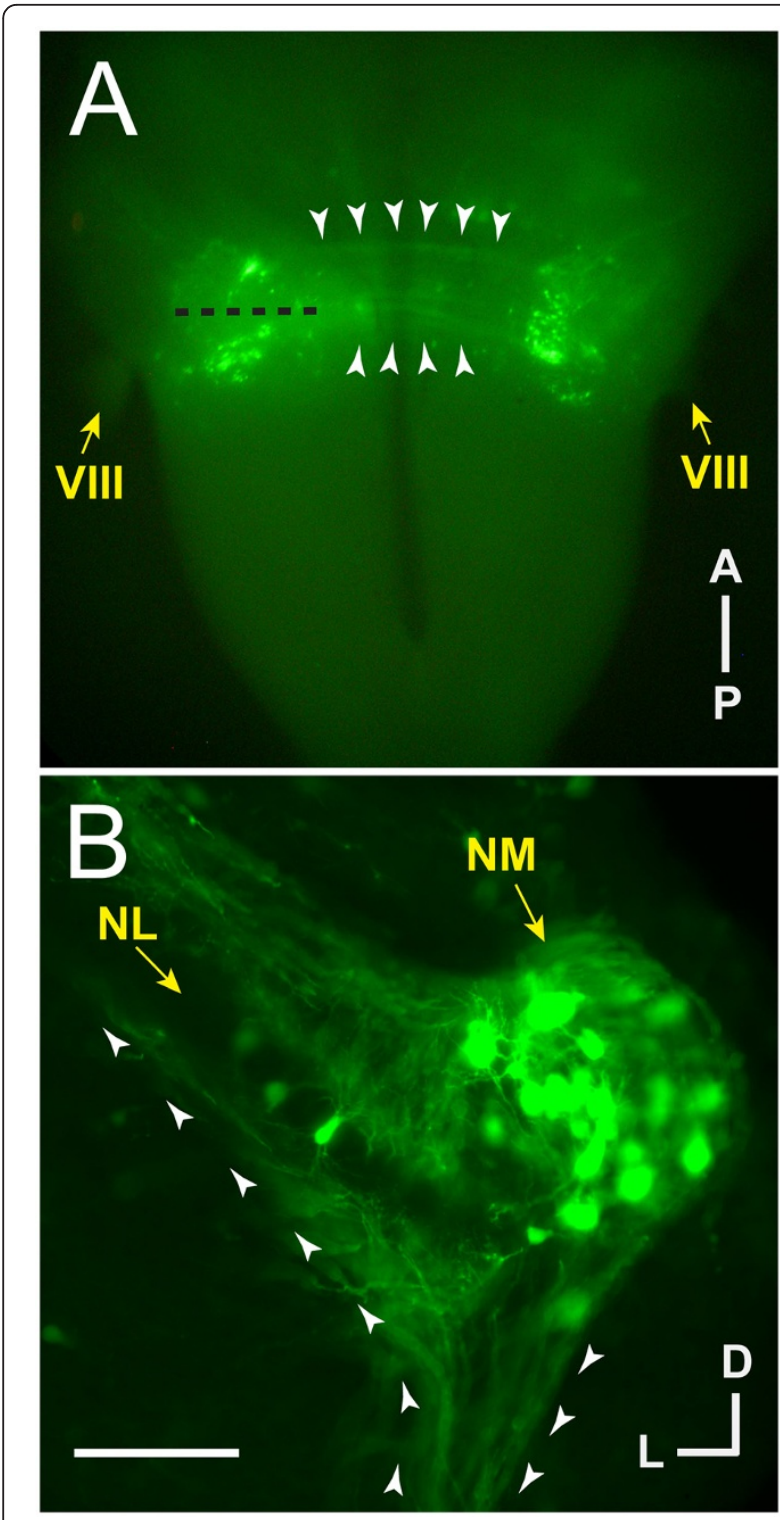

Figure $\mathbf{2}$ Transfection is limited to auditory nuclei as seen by EGFP fluorescence. (A) Dissected chick brainstem at E10 following in ovo electroporation at E2. Bilateral auditory nuclei are EGFP positive, as are the axons connecting NM to contralateral NL (white arrowheads). (B) Coronal section of E10 chick brainstem (left side) at approximately the level shown by a black dashed line in (A) shows transfection is extensive in but not limited to NM cells and their axons. In the section shown here, three NL cells and their bipolar tufts of dendrites within the cellular monolayer are visible by EGFP fluorescence. (A, B) White arrowheads delineate the margins of contralateral NM axons, and are oriented in (B) to indicate anterograde direction from NM origin to contralateral target. Scale bar $=1 \mathrm{~mm}$ in (A) and $100 \mu \mathrm{m}$ in (B).
(Figure 2B), the number of transfected NL cells were outnumbered over 10:1 by NM transfected cells. A total of 24 electroporated embryos met inclusion criteria (described in Methods) and were used in the axon targeting analysis, while 57 were used at least in part for anatomical analyses.

\section{Misexpression of EphB2 impairs axon targeting and NL morphogenesis}

Axon targeting in the NM-NL pathway was analyzed in E10 embryos after transfection. Each embryo was considered a single data point, and targeting errors were quantified across the central region of each right and left NL. As expected, control embryos with EGFP transfection showed few contralateral NM axons in the dorsal region of the NL neuropil (Figure 3A, A'), with $2.85 \pm 0.80$ errors per $400 \mu \mathrm{m}$ of NL $(n=7$; Figure $3 \mathrm{D})$. In embryos transfected with a full-length wild type EphB2 (Figure 3B, B') the mean number of targeting errors was $7.17 \pm 1.70$ per $400 \mu \mathrm{m}$ of NL $(n=6$; Figure 3D), which did not significantly differ from EGFP controls $(P=0.09$; Student's $t$-test). To test the effect of reduced EphB2 signaling, we examined embryos transfected with kiEphB2, which acts as a dominant negative to inhibit forward signaling by interfering with endogenous receptor function [47] but acts similar to EphB2 in its potential to activate reverse signaling. We found that misexpression with kiEphB2 resulted in a significant increase in axon targeting errors from NM to contralateral NL (Figure 3C, C'). The mean number of targeting errors was $14.73 \pm 1.63$ per $400 \mu \mathrm{m}$ of NL $(n=11$; Figure $3 \mathrm{D})$, which was significantly greater than that seen in control embryos $(P<0.0001)$ or in EphB2transfected embryos $(P=0.0028)$. The significant increase in errors associated with kiEphB2 compared to EphB2 suggests that EphB2 forward signaling selectively affects targeting of NM axons to appropriate dendritic targets in NL and that it is a cell-autonomous effect since NM (axons) rather than NL (target) cells were transfected.

We examined the morphology of auditory brainstem nuclei in electroporated embryos. During data collection, abnormal NL morphologies were observed in which NL was either not organized into a flattened cellular monolayer and/or was reduced in length. In some instances, ipsilateral NM and NL were positioned in closer proximity to each other than expected for the age examined. The percentages of embryos within each group meeting any of these criteria for atypical NM-NL morphology are shown in Figure 3E. Overall, 75\% (12 of 16) of embryos expressing functional EphB2 plasmids had an atypical NL morphology compared to $6 \%(n=17)$ and $4 \%$ $(n=24)$ of embryos transfected with EGFP alone or kiEphB2, respectively. Unlike EphB2 misexpression 

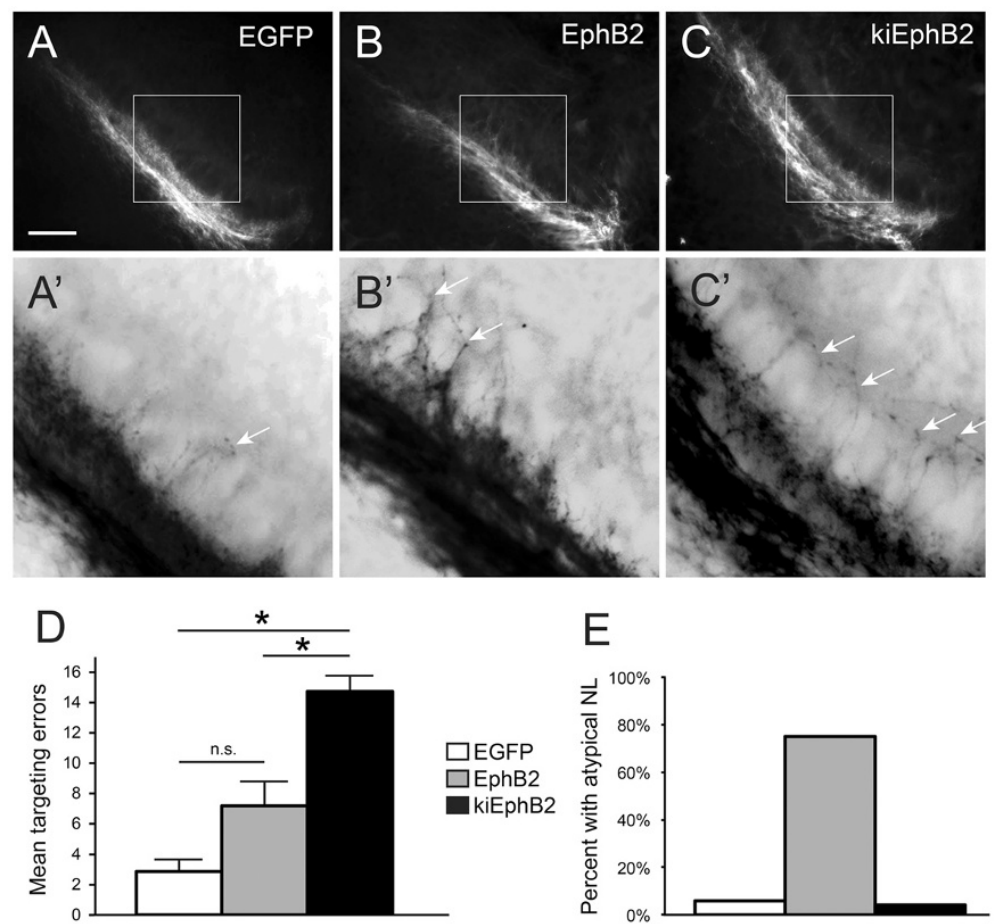

Figure 3 Targeting errors are increased when EphB2 is misexpressed during development. (A-C, $\left.\mathbf{A}^{\prime}-\mathbf{C}^{\prime}\right)$ RDA trace of left-sided NL in E10 embryos following E2 transfection of EGFP control $\left(\mathbf{A}, \mathbf{A}^{\prime}\right)$, full-length EphB2 (B, $\left.\mathbf{B}^{\prime}\right)$, or kiEphB2 $\left(\mathbf{C}, \mathbf{C}^{\prime}\right)$ plasmid. $(\mathbf{A}, \mathbf{B}, \mathbf{C})$ are original $20 \mathrm{X}$ images with the outlined box expanded and color-inverted in $\left(\mathbf{A}^{\prime}, \mathbf{B}^{\prime}, \mathbf{C}^{\prime}\right)$ to highlight fine processes of single axons crossing the NL cell body layer inappropriately (white arrows). (D) Quantification of the mean number of axon targeting errors per group with SEM bars. (E) Percentage of embryos in each group demonstrating atypical features of NL morphology, including a reduced length and/or a disorganized cellular layer. Scale bar $=100 \mu \mathrm{m}$ in $(\mathbf{A}-\mathbf{C})$ and $35 \mu \mathrm{m}$ in $\left(\mathbf{A}^{\prime}-\mathbf{C}^{\prime}\right)$

studies, there were no abnormal morphologies associated with kiEphB2 misexpression, suggesting that these effects arise from an increase in EphB2 forward signaling. In EphB2 transfected embryos, though the average increase in errors was not significant compared to controls, those with the greater number of targeting errors were also those with appreciable but not exclusionary abnormalities in NL morphology.

\section{Eph fusion proteins as inhibitors of Eph signaling}

The electroporation studies suggest that EphB2 forward signaling regulates both axon guidance and auditory brainstem morphogenesis. We further tested this possibility by inhibiting forward signaling during the time that NM axons approach their contralateral NL target. We used unclustered soluble Eph receptor fusion proteins to inhibit forward signaling by endogenous ligands. The fusion proteins only differ at their C-terminal region, either having or lacking an Eph receptor extracellular domain, with an identical IgG-Fc region at the $\mathrm{N}$-terminus. We first demonstrated that EphB1-Fc has the expected binding properties based on known expression patterns of ephrin-B ligands in the chick auditory brainstem (Figure 4). Adjacent sections of cryosectioned tissue were incubated with either EphB1-Fc or IgG-Fc, followed by labeling with the same secondary fluorescent anti-Fc antibody. Nuclear counterstaining with bisbenzamide was used to identify NL (Figure 4A,' B'). While IgG-Fc treatment showed no immunolabeling (Figure 4A), we found that EphB1-Fc preferentially binds regions of the auditory brainstem where ephrin-B ligands are highly expressed at the age examined, including the midline and NM-NL neuropil (Figure 4B).

\section{Broad inhibition of Eph signaling impairs axon targeting and NL morphogenesis}

Because soluble fusion proteins are subject to degradation, the competitive inhibition assays were all performed in an ex ovo preparation that provided access to the brainstem at later embryonic ages and permitted injections in a localized region over the course of several days. Fusion proteins solubilized in PBS were injected into the developing hindbrain and fourth ventricle for four consecutive days from E6 to E9, when contralateral-projecting NM axons have already crossed the midline and are approaching their NL target [13]. Since it is possible that multiple Eph-ephrin pathways coordinate axon targeting of this pathway, we performed 


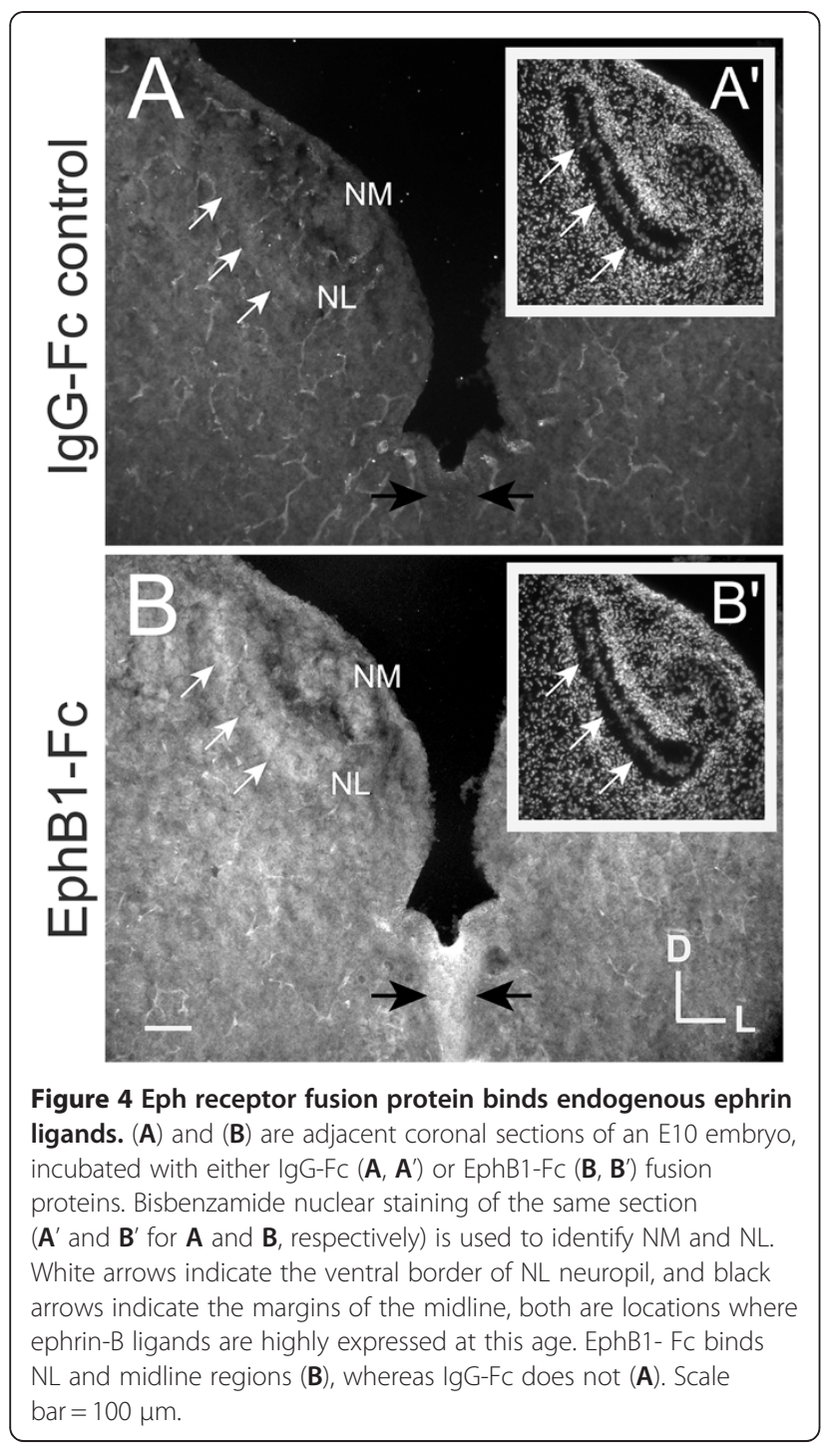

differential inhibition of the subclasses. EphB1-Fc was used to exclusively inhibit EphB forward signaling because EphB1 only binds ephrin-B ligands. EphA4-Fc was used to inhibit all EphA and EphB forward signaling because, in addition to ephrin-A ligands, EphA4 binds ephrin-B2, a ligand for both subclasses of Eph receptors. Our goal here was to discriminate between the effects of the receptor subclasses, particularly whether EphB signaling was unique or overlapping with EphA signaling. For negative controls, we had an untreated group and a group that received injections of human IgG-Fc. A total of 29 samples were used in the axon targeting analysis and 35 were used in the analysis of anatomical measurements. Representative images and quantification of targeting errors for each condition are shown in Figure 5.

Embryos with no injections that were prepared ex ovo had a mean of 9.80 errors \pm 1.48 per $400 \mu \mathrm{m} \mathrm{NL} \mathrm{(} \mathrm{n}=10$; Figure $5 \mathrm{~A}$ ), an error rate that did not differ significantly from control embryos treated with IgG-Fc (Figure 5B; $9.86 \pm 1.55$ per $400 \mu \mathrm{m} \mathrm{NL}, \mathrm{n}=7 ; P=0.99)$. In contrast, we found there was a significant increase in axon targeting errors from NM to contralateral NL after treatment with EphB1-Fc (Figure 5C; $16.75 \pm 3.22$ per $400 \mu \mathrm{m} \mathrm{NL}$, $\mathrm{n}=8, \quad P=0.04$ ) and with EphA4-Fc (Figure 5D; $26.25 \pm 3.09$ per $400 \mu \mathrm{m} \mathrm{NL}, \mathrm{n}=4, P=0.0009$ ) as compared to IgG-Fc controls. The effect of EphA4-Fc was significantly greater than that of EphB1-Fc $(P=0.02$; data summarized in Figure 5E). Often multiple axons were seen crossing together in EphA4-Fc treated embryos (Figure 5D) so the number of errors is likely underreported due to our conservative analysis. These data suggest that forward signaling through $\mathrm{Eph}$ receptors is necessary for appropriate axon targeting, and that the EphA and EphB receptor classes make individual contributions to axon targeting in the NM-NL pathway.

We found that, similar to plasmid electroporated embryos, NL was often disorganized following EphB1-Fc or EphA4-Fc injection. However, unlike the embryos subjected to plasmid electroporation, there were also appreciable targeting abnormalities of NM axons at the ventrolateral neuropil of NL that were not related to crossing the NL cell body layer. The percentages of embryos having any of these atypical morphologies are shown in Figure 5F. Overall, 82\% (9 of 11) of EphB1-Fc and 75\% (6 of 8) of EphA4-Fc injected embryos were atypical, compared to $17 \%$ of combined controls $(n=18)$. Of the EphB1-Fc treated embryos, a majority of the atypical morphologies (7 of 9) were limited to aberrant projections along the ventrolateral NL neuropil (Figure 6B) with a normal NL monolayer, whereas NL formation itself appeared affected more often in EphA4Fc treated embryos (4 of 6; Figure 6C).

\section{Impaired development of auditory brainstem nuclei}

When embryos were transfected with functional, fulllength EphB2, the development of auditory nuclei was often impaired, with 75\% (12 of 16) of transfected embryos showing abnormal NL morphology (Figures 3E, $6 \mathrm{D})$. This observation contrasts greatly with controls, as only $6 \%(n=17)$ and $4 \%(n=24)$ of embryos transfected with EGFP alone or kiEphB2, respectively, showed abnormal morphology. There was wide variation in the observed range of morphological defects, from merely a reduced NL extent without disorganization (two cases) to a severe malformation of both auditory nuclei (two cases) where NM and NL could not definitively be identified. In total, six samples were excluded from axon targeting analyses for not meeting the necessary criteria, as NL was either not identifiable or not presenting as a monolayer with discrete ventral and dorsal neuropil. Similar changes in NL were seen with ex ovo inhibition of EphA and EphB receptors together, where $75 \%$ of the 


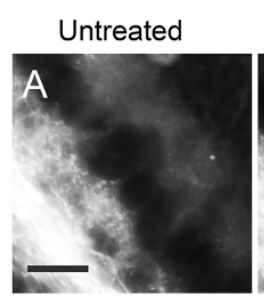

E

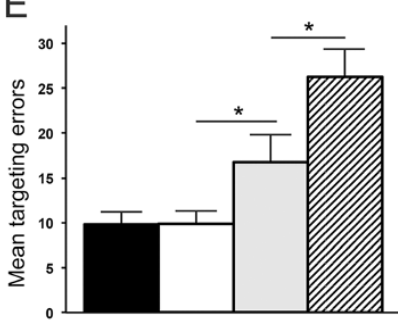

$\lg \mathrm{G}-\mathrm{Fc}$
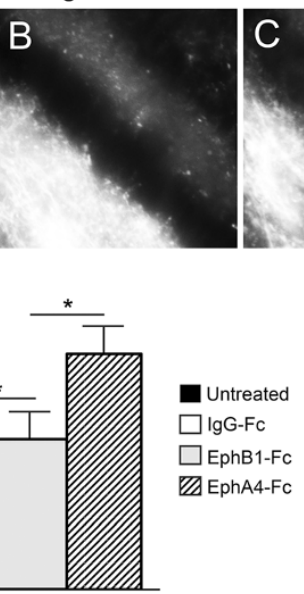

EphB1-Fc

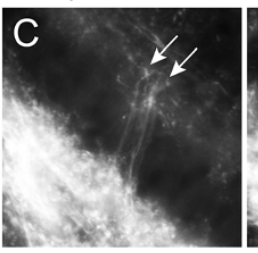

F

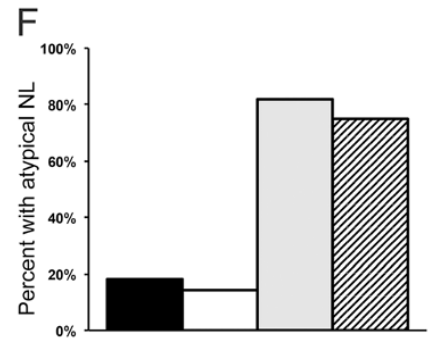

Figure 5 Treatment with Eph receptor fusion protein results in increased targeting errors and atypical NL morphology. (A-D) RDA tracings of contralateral-projecting NM axons at E10 in untreated embryos (A) or embryos treated during E6 to E9 with lgG-Fc control (B), EphB1-Fc (C), or EphA4-Fc (D). Axonal processes inappropriately cross the NL cell body layer, terminating in the dorsal NL neuropil in embryos treated with EphB1-Fc or EphA4-Fc (white arrows, C, D). (E) Quantification of mean axon targeting errors and (F) percentage of embryos with an atypical NL (including either atypical NL morphology or atypical NL border or both). Scale bar $=25 \mu \mathrm{m}$.

EphA4-Fc injection cases $(n=8)$ had some level of disorganization at the NL layer (Figures $5 \mathrm{~F}$ and $6 \mathrm{E}$ ), two of which were severe enough to exclude them from analysis of targeting errors. The remaining samples with acceptable axon tracing often displayed an unusual pattern of axonal projections that appeared to extend past NL and terminate in a laterally adjacent brainstem region. Of embryos receiving EphB1-Fc injections to inhibit EphB receptors alone, only $18 \%$ displayed an abnormal NL morphology, but aberrant laterally projecting NM axons were observed in $72 \%$ of the cases $(n=11$; Figure 6B) and these axons were more numerous and appeared to extend farther than in cases with EphA4-Fc injection.

We found that $17 \%$ of the ex ovo control cases $(n=18)$ also displayed some aberrant lateral projections but to a much lesser extent than treated embryos. These aberrant lateral projections were never observed with any of the in ovo preparations. Thus, it is possible the impaired lateral targeting is permitted within the ex ovo preparation and is exacerbated by the inhibition of Eph signaling. Several anatomical variables were quantified, including rostrocaudal and mediolateral lengths of NL (Figure 6E, F) as well as distance and angle between NM and NL (not significant, data not shown). For embryos overexpressing wild-type EphB2, measures were consistently reduced across variables as compared to controls. The rostrocaudal and mediolateral extents of NL were both significantly reduced $(\mathrm{p}=0.03$ and $P=0.001$ respectively). For embryos treated with EphA4-Fc, the rostrocaudal extent of NL was significantly reduced compared to IgG-Fc controls $(P=0.0169)$. An example of a severely reduced NL extent without NL disorganization is shown in Figure 6D, and a disorganized NL also having a reduced NL extent is shown in Figure 6C. Group data for rostrocaudal and mediolateral extents of NL are presented in Figure 6E, F. Internal controls were used to analyze in ovo versus ex ovo experiments separately to exclude any differences associated with the preparations.

\section{Discussion}

In this study, we tested the role of EphB signaling in the guidance of NM axons to dorsal versus ventral dendritic regions of NL and in the morphogenesis of these auditory nuclei. We found that reduction of EphB2 forward signaling, either by kiEphB2 transfection or by local inhibition with soluble fusion proteins, resulted in a significant increase in the number of mistargeted contralateral NM axons as compared to controls. In addition, there were significantly more targeting errors when forward signaling through both EphA and EphB receptor subclasses were inhibited compared to inhibition of EphB receptors alone. While EphB2 electroporation, performed at E2, did not alter axon targeting, we found that it resulted in abnormal NL morphology in which NL was significantly shorter along both rostrocaudal and mediolateral brain axes than in controls. Morphological defects were also seen with fusion protein treatment, performed from E6 to E9. EphB1-Fc injections resulted in markedly aberrant NM projections at E10 that exceeded the contralateral NL boundary and projected laterally. EphA4-Fc injections resulted in malformed NL lamina, and aberrant laterally projecting axons, though less prominent than in EphB1-Fc treated 

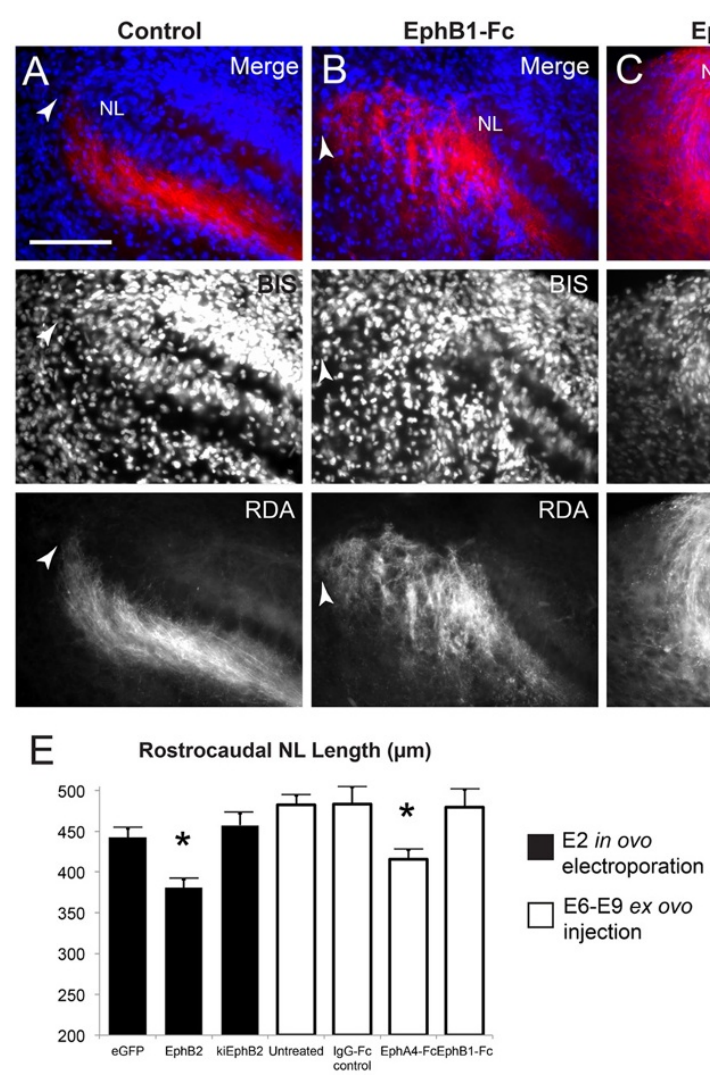

EphA4-Fc
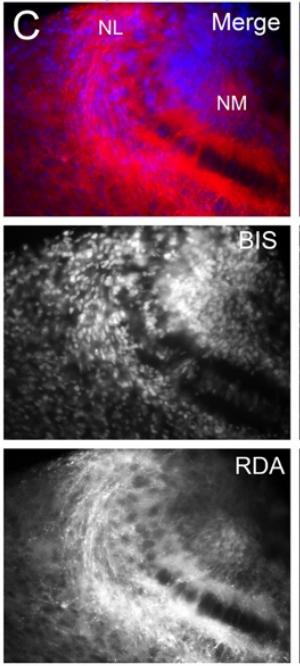

$\mathrm{F}$

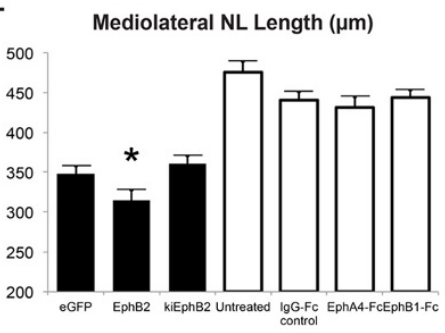

Figure 6 Development of NL is affected by impaired Eph receptor signaling. Representative 40X images of lateral NL following RDA midline tracing of E10 control embryos (A), embryos treated with EphB1-Fc (B), EphA4-Fc (C), or transfected with full-length EphB2 (D). Top panels are a merge of bisbenzamide (BIS, blue) nuclear counterstaining and RDA (red) fluorescence from labeled contralateral NM axons; both channels are shown individually in respective middle and lower panels. NL is normally an elongated, flattened layer with a lateral border (leftmost on these images) well defined by contralateral NM axons (white arrowhead in A). Treatment with EphB1-Fc (B) results in disorganized NM axons projecting lateral to the NL border (white arrowhead in B). Treatment with EphA4-Fc results in an abnormal NL morphology, where the mediolateral length is reduced and the lateral aspect is disorganized and not flattened (C). NM is normally found dorsomedial to NL and not within the same imaging field at 40X magnification, but the positioning of NM relative to NL is altered following transfection with full-length EphB2 at E2 (D) or treatment with EphA4-Fc from E6 to E9 (C). Measurements of NL (E, F) demonstrate the reduced extent of NL along both rostrocaudal $(\mathbf{E})$ and mediolateral $(\mathbf{F})$ axes when EphB2 is overexpressed from E2, and along the rostrocaudal axis (E) when all Eph receptors are inhibited with EphA4-Fc injection from E6 to E9. Scale bar $=100 \mu \mathrm{m}$, left is lateral and dorsal is up.

embryos. NL was significantly shorter along the rostrocaudal axis with no change in mediolateral length compared to IgG-Fc injected and untreated controls. Together, these studies demonstrate several distinct functions for Eph proteins in the formation and connections of NM and NL.

\section{Forward EphB2 signaling guides NM axons}

We previously showed that misexpression of EphA4 resulted in a significant number of targeting errors in which contralateral NM axons extended into the dorsal NL neuropil [17]. The expression of EphA4 in NL and not NM, together with the observation that EphA4 and kiEphA4 had similar effects, suggested a noncell-autonomous role in which EphA4 in the target stimulates NM attraction through reverse signaling in NM axons. While those studies were initially motivated by the asymmetric expression of EphA4 in NL neuropil regions [44], the finding that many NM axons retained their appropriate targeting after misexpression prompted us to consider the potential roles of other Eph proteins. While EphA4 was unique among these proteins in its asymmetry, both EphB2 and ephrin-B1 showed high expression levels in dorsal and ventral NL neuropil, and EphB2 and ephrin-B2 were seen in NM axons [27].

The electroporation studies carried out here examined the role of EphB2 in NM axons. We found that kiEphB2, but not EphB2, increased targeting errors by NM axon branches into contralateral dorsal NL. Because kiEphB2 decreases forward signaling while EphB2 increases it, our results suggest that forward signaling through EphB2 in NM axons is needed for the restriction of NM axons. The observation that EphB2 overexpression in NM axons did not have an opposite effect likely reflects 
the normally high precision in NM axon segregation. Together with our EphA4 study, these results suggest that bidirectional Eph signaling regulates the binaural segregation of NM axons in NL.

Based on our previous expression analysis [27], forward signaling through EphB2 in NM axons could be elicited through (1) ephrin-B1, which might provide chemorepulsive signals to NM axons entering the ventral NL neuropil, and/or (2) by ephrin-B2, which is expressed in NL cell bodies and could act as a barrier to axons to prevent them from reaching the dorsal neuropil layer. This latter possibility could provide an effective barrier for both ipsilateral and contralateral NM-NL projections. As ephrin-B2 is expressed in NM axons [27], an attractive reverse signaling cue from EphA4 in the dorsal NL neuropil would then be most effective in axons dorsal to NL (that is, from ipsilateral NM), which were not exposed to these chemorepulsive cues.

The expression of EphB receptors and ephrin-B ligands in both axon and target suggests several possible roles for EphB signaling. In addition to axon guidance, Eph-ephrin signaling, and in particular, EphB signaling, has a well-documented role in synaptogenesis and synaptic plasticity [48-61]. Because NM-NL synapses form at about E10, just after axons reach the neuropil area, the guidance of axons to these regions may be linked to formation of synapses in the correct regions. Moreover, forward and reverse signaling may influence each other due to interactions in cis, whereby ephrins can bind to Eph receptors within the same cell $[62,63]$ or segregate laterally into distinct signaling domains [64,65]. These interactions can lead to downstream signaling and can alter the availability of either class for binding with proteins in trans $[62,63,66,67]$.

\section{EphA and EphB signaling provide distinct axon guidance cues}

In our fusion protein studies, we found that infusion of EphA4-Fc resulted in significantly more targeting errors in the NM-NL pathway than infusion of EphB1-Fc, suggesting that inhibition of EphA and EphB signaling is more effective than inhibition of EphB signaling alone. These results are consistent with the observation of extensive targeting errors with EphA4 electroporation [17] and suggest that in addition to EphB signaling and EphA4-ephrin-B2 interactions, EphA4 may facilitate axon guidance through interactions with ephrin-A ligands. We have previously demonstrated expression of ephrin-A2 in the auditory nerve and NL neuropil during the formation of NM-NL projections [45], indicating its feasibility as a candidate. Coordinated function between $\mathrm{A}$ and $\mathrm{B}$ classes has been shown to guide orderly projection patterns, notably in retinotectal projections [68-72]. Though we postulate here about loss of normal EphB2 repulsive cues, it is also likely EphA4 attractive cues are affected with EphA4-Fc injection and it would be interesting to explore this by analyzing ipsilateral NM-NL projections.

While our study focused on targeting of NM axons to distinct dorsal versus ventral NL regions, selective inhibition of the EphB class of receptors revealed an additional dimension of axon guidance for contralaterally projecting $\mathrm{NM}$ axons along the mediolateral axis. In particular, EphB fusion proteins resulted in pronounced lateral overgrowth by NM axons. Unlike the electroporation studies where misexpression was generally limited to NM axons and led to aberrant dorsoventral targeting, injection of fusion proteins into the hindbrain produced a broader inhibition that likely included EphB receptors in the NL neuropil. The observation of lateral overgrowth of NM axons using this approach may thus indicate that EphB signals arising in or near NL normally provide chemorepulsive cues that limit lateral growth.

\section{Morphogenesis of auditory nuclei}

In addition to axon targeting errors, manipulations of Eph signaling also resulted in stereotyped morphological abnormalities. When EphB2 forward signaling was increased using plasmid electroporation at E2, prior to cellular migration and NL flattening into a monolayer, we observed a significant reduction in the size of NL. This effect may be a result of impaired migration of $\mathrm{NL}$ cells from the auditory anlage and/or from a reduction in total NL cells either by changes in cell fate specification or increased cell death. During normal development, NL undergoes extensive (84\%) cell death as the monolayer forms [3]. Further analysis of changes in nuclei density and cell movement over time would be required to evaluate this possibility rigorously. NL was often disorganized, but in many cases the laminar appearance of NL was normal. Given that the majority of transfected cells were in NM, these results suggest a non-cell-autonomous role for EphB2 that would implicate NM-NL interactions in generating the appropriate morphology.

Our observations are consistent with previous reports that EphB/ephrin-B signaling has been shown to guide normal cellular migration in mammalian neocortex, hippocampus and cerebellum [73], avian and Xenopus neural crest [74-76], and zebrafish notochord [77] and hindbrain [78], whereby a contact repulsion mechanism is implicated [79,80]. EphB2 forward signaling in particular is responsible for lamination of hippocampal dentate gyrus cells, another brain region with distinct dorsal-ventral connectivity [81]. Though Eph-ephrin signaling is bidirectional [82], the abnormal morphologies were not seen with kiEphB2 transfection, where forward but not reverse signaling was impaired. Similarly disorganized NM-NL nuclei were also observed when EphA4 
but not kiEphA4 was overexpressed [17] further implicating Eph receptor forward signaling in normal development. Together, these data suggest that forward signaling through EphA and EphB, possibly through their common ligand ephrin-B2, is necessary for the normal separation and organization of NM and NL. Indeed, inhibition of EphB forward signaling alone during E6 to E9 typically did not result in malformed nuclei, whereas inhibition of both subclasses together during E6 to E9 was sufficient to produce malformed nuclei at E10. Because NL lamination occurs when NM axons approach $\mathrm{NL}$, it remains unclear whether either process is dependent on the other. Such an interaction is consistent with the observation that EphA4-Fc treated embryos often resulted in an abnormal NL morphology and also had a significant increase in targeting errors compared to EphB1-Fc treated embryos. Since multiple axons were often found crossing together following EphA4-Fc treatment, the possibility exists that fasciculation cues may also have been affected. However, because embryos with severely malformed nuclei did not meet inclusion criteria for axon targeting analysis, it is difficult to provide more than a qualitative correlation. Our findings suggest that integrated actions of Eph receptor signaling are necessary for migration of auditory nuclei precursor cells during development and that in turn, appropriate migration may be necessary for axonal target specification.

\section{Morphogenesis relies on Eph signaling at several developmental stages}

When EphB forward signaling was inhibited using fusion proteins in ex ovo preparations from E6 to E9, though NL lamination appeared normal, we observed a tendency for NM axons to overshoot the lateral boundary of their contralateral NL target, suggesting that during normal development ephrin-B2 expressing axons may be limited to ventral NL neuropil by EphB2 forward signaling in NL cells. However, when forward signaling through both EphA and EphB was inhibited by EphA4-Fc injection, we observed more significant morphological defects. Similar to results for EphB2 electroporation, there was a reduced rostrocaudal extent of NL compared to controls. In contrast, the mediolateral extent was unchanged, suggesting that this axis is set earlier in development, while rostrocaudal extension may be more protracted.

The differences in morphological defects between treatment groups suggest that Eph proteins have distinct roles during different developmental phases. Effects seen with electroporation at E2 could result from early morphogenetic events, such as cell proliferation and formation of the auditory anlage from precursors in distinct regions $[2,46]$, as well as later events, such as separation of NM and NL from the anlage and flattening of the NL cell body layer [15]. In contrast, effects of fusion protein infusion at E6 to E9 reflect only these later events. While electroporation targets mainly NM cells, fusion proteins diffuse broadly within the brainstem and may affect NM and NL as well as their surrounding regions. Thus the cell autonomy of these effects is difficult to determine. The observation that EphB2 receptor overexpression in NM led to morphologic defects in NL suggests a role for reverse signaling, but could also indicate changes in the levels of available ephrins in NM cells due to interactions with exogenous EphB2. Though the exact mechanisms involved here are unknown, perturbations to migratory pathways of neocortex, cerebellum and hippocampus are seen with loss of EphB2 and ephrin-B signaling and may be linked to changes in expression, recruitment and/or signaling of extracellular matrix proteins such as Reelin [73,81]. Migrating cortical neurons appear to use EphB versus EphA signaling differentially in determining radial versus tangential movement, respectively [80]. Likewise, our results suggest that Eph proteins have a significant role in the formation of the auditory brainstem circuit at several developmental time points, along discrete axes and for distinct developmental events.

\section{Conclusions}

Our experimental results together with known developmental events seen during NM-NL development are summarized in Figure 7. The precursors for NM and NL coalesce in the auditory anlage by E5 $[15,46]$. In the protracted development of this pathway, NM and NL undergo morphogenetic changes while NM axons simultaneously grow toward their bilateral targets. By E10, precise topographic connections have formed with ipsilateral and contralateral contacts at distinct regions of respective dorsal and ventral dendrites.

Together with previous expression and misexpression studies, our results highlight the complex interactions between Eph molecules in NM-NL development. In our model, we propose that EphA4 signaling in dorsal but not ventral NL neuropil is an attractive cue to ipsilateral NM axons, whereas the repulsive nature of EphB signaling acts at the NL cell body layer disallowing axons on either side from crossing the NL monolayer. The segregation of ipsilateral and contralateral NM inputs to NL could thus arise from the distinct expression patterns of EphA4 and EphB2 along with the opposing effects of these proteins on axon growth. This view is consistent with data on dorsoventral targeting (present study and [17]), midline axon guidance [13], and the data presented here on lateral growth of NM axons; it also takes into account the spatiotemporal expression of Eph family proteins in the developing pathway $[27,44]$. Several other factors must be considered before we can obtain a complete account of the mechanisms that give rise to this highly ordered neural pathway. Significantly, the link 


\section{Coordinated Eph-ephrin signaling during NM-NL development}

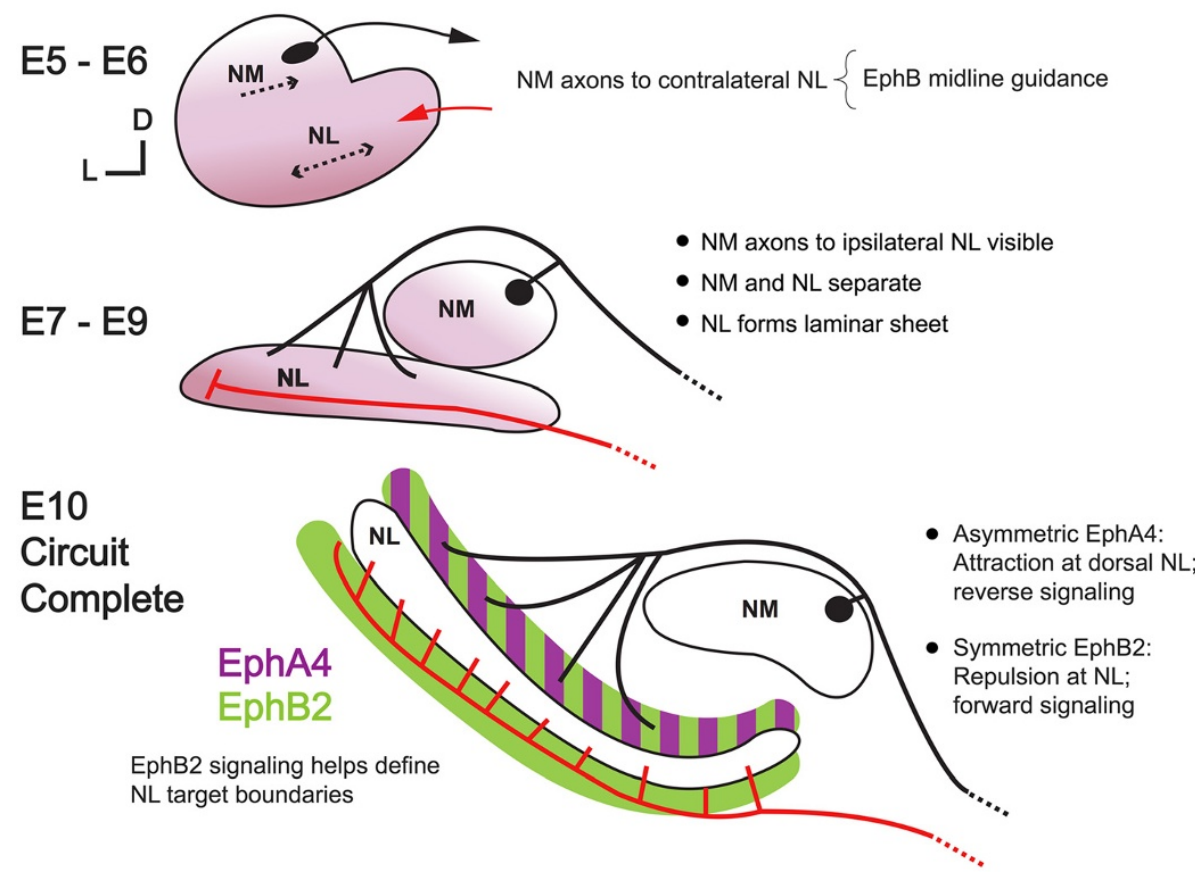

Figure 7 Illustration of Eph-ephrin driven events important for normal development of the NM-NL circuit. Left-sided NM and NL are schematized in a coronal view similar to sections shown in Figures1, 2, 3, 4, 5, 6 with dorsal up and medial to the right. Migratory and axon targeting events during embryonic days 5 through 10 (E5 to E10) are described. The black line represents ipsilateral NM projections (that is, those arising from the left side) and the red line represents contralateral NM projections (that is, those arising from the right side, not shown).

between morphogenesis of NM and NL and the concomitant growth of axons to precise targets is not understood. Our studies suggest that a small set of Eph proteins functions in both processes in distinct ways and that appropriate targeting could be dependent on maturation of the target. Though all Eph signaling inhibition treatments caused targeting errors, there were more errors when all signaling was blocked and unique morphologic outcomes associated with each condition. The increase in targeting errors when all Eph signaling was blocked versus EphB signaling alone might reflect an amplified effect of the same targeting mechanism, a result of the abnormal morphology per se, or both. While it is not yet possible to determine how these proteins act at each stage, or which other molecules contribute to the assembly of this circuit, our results, together with previous studies, suggest that coordinated Eph signaling at multiple steps is needed for the formation, connectivity and boundary specification of the NM-NL circuit.

\section{Methods}

\section{Embryos}

Fertilized brown Leghorn chicken eggs (Gallus domesticus) were obtained from AA Laboratories (Westminster, CA, USA) and stored at room temperature for up to two days prior to use. To initiate embryonic development, the eggs were placed in a rotating incubator at $39^{\circ} \mathrm{C}$ with a relative humidity above $70 \%$. Chick embryos were either electroporated in ovo at E2 or transferred at E3 to a culture dish for ex ovo experimentation at E6 to E9. Ex ovo culture dishes were maintained in a non-rotating incubation chamber of similar temperature and humidity, allowing access to the developing embryo at later ages than the in ovo preparation. Each ex ovo culture preparation consisted of a disinfected polystyrene weigh dish ( 3.5 X $3.5 \times 1$ in.) into which the egg was opened, and a sterile square disposable petri dish bottom (100 X $100 \mathrm{X} 15 \mathrm{~mm}$ ) used as a lid. All embryos were sacrificed at E10 and the brainstem carefully dissected for in vitro whole mount axon tracing.

\section{In ovo electroporation}

Eggs were removed from the rotating incubator at E2 and a small circular window was cut into the side of the eggshell following reinforcement with tape and removal of $3 \mathrm{~mL}$ thin albumin. Using a modified 25-guage hypodermic needle, a small amount of 4\% India ink (in phosphate buffered saline (PBS)) was injected directly beneath the embryo to permit visualization. The vitelline membrane was removed with a fine tungsten needle and 
a small incision was made into the embryonic roof plate at the level of rhombomere 5 to provide access to the neural tube. Sterile PBS was placed over the area of interest to enhance electrical current and protect the embryo and underlying membranes from electrical burns. Paired needle-style gold-plated electrodes (Genetrodes, Harvard Apparatus, Holliston, MA USA) were positioned straddling the area of interest, approximately 2 to $3 \mathrm{~mm}$ apart. Plasmid DNA ( 1 to $3 \mu \mathrm{g} / \mu \mathrm{L}$ in Tris/ EDTA), colored with a small amount of Fast Green dye, was injected into the neural tube opening using a 1.2 $\mathrm{mm}$ pulled glass pipette attached to a Picospritzer (Parker Hannifin Corporation, Irvine, CA USA). No more than 100 to $200 \mathrm{~nL}$ of plasmid DNA was delivered using a series of (typically 2 to 6) injections of 20 to $50 \mathrm{~ms}$ duration and $20 \mathrm{psi}$. Voltage was delivered using a BTX electroporator, with amplitude of 9 to 12 Volts and 50-ms duration, in trains of four to six pulses of $100 \mathrm{~ms}$ intervals. A total of 20 to 30 pulse trains were delivered for each embryo, with polarity switched between pulse trains in order to achieve bilateral transfection. All openings in the eggshell were sealed with tape, and the eggs were placed in a humid, non-rotating $39^{\circ} \mathrm{C}$ incubation chamber for an additional eight days.

\section{Plasmids}

Plasmid vectors were used to introduce DNA via in ovo electroporation. Full-length EphB2 was cloned into pCAX at the EcoR1 site and co-transfected with pCAXEGFP. The pCAX construct encodes chicken $\beta$-actin promoter, a CMV-IE enhancer, polycloning sites and poly-A signal. Full-length EphB2 or kinase inactive EphB2 (kiEphB2; provided by E. Pasquale, SanfordBurnham Institute, La Jolla, CA, USA) containing a point mutation in the intracellular kinase domain was cloned into the pMES vector at the EcoR1 site. The pMES construct contains a chicken $\beta$-actin promoter, a CMV-IE enhancer and also encodes an EGFP reporter with an internal ribosomal entry site. As a negative control, embryos were transfected with pCAX-EGFP alone. Transfection was assessed by examination of EGFP fluorescence in dissected brainstems and in sectioned material using an epifluorescent microscope. In addition, we performed immunostaining on transfected embryos using methods described previously for EphA4 and EphB2 detection following electroporation $[13,17,44]$.

\section{Recombinant fusion protein injections}

A soluble recombinant protein containing the EphB1 receptor extracellular domain fused to the Fc region of Human IgG (rat EphB1-Fc; R\&D Systems, Minneanapolis, MN, USA) was used to inhibit forward signaling through EphB receptors. Additionally, mouse EphA4-Fc (R\&D systems) was used to inhibit forward signaling through EphA and EphB receptors. Recombinant proteins were diluted to $10 \mu \mathrm{g} / \mathrm{mL}$ in sterile $1 X$ PBS and a small amount of methylene blue powder (Sigma-Aldrich, St. Louis, MO, USA) was dissolved into the solution at $37^{\circ} \mathrm{C}$ immediately prior to use to aid with injection visibility. Final solution was injected into the developing hindbrain at the floor of the fourth ventricle with a $1.2 \mathrm{~mm}$ pulled glass pipette attached to a Picospritzer using pulses of 20 to $200 \mathrm{~ms}$ duration and intensity of 20 psi. Injections were made for four consecutive days, E6 to E9, when NM axons have already crossed the midline and are approaching their contralateral NL target. The total volume injected varied from approximately 1.5 to $5.5 \mu \mathrm{L}$ per embryo for respective E6 to E9 ages. Human IgG1-Fc (R\&D Systems) was used as a negative control. Fusion protein binding specificity was confirmed by incubation of fixed $30 \mu \mathrm{m}$ cryosections with EphB1Fc or IgG-Fc overnight, followed by secondary (anti-Fc) fluorescent antibody incubation for two hours.

\section{Ex vivo axon tracing}

Axon tracing was used to identify and quantify targeting errors. E10 chick embryos were removed from the egg or the ex ovo culture dish and the brainstem quickly dissected in oxygenated artificial cerebrospinal fluid (aCSF; $130 \mathrm{mM} \mathrm{NaCl}, 3 \mathrm{mM} \mathrm{KCl}, 1.2 \mathrm{mM} \mathrm{KH} \mathrm{KO}_{4}, 20 \mathrm{mM}$ $\mathrm{NaHCO}_{3}, 3 \mathrm{mM}$ HEPES, $10 \mathrm{mM}$ Glucose, $2 \mathrm{mM} \mathrm{CaCl}$, $1.3 \mathrm{mM} \mathrm{MgSO}_{4}$ ). A pulled glass micropipette with an approximately $10 \mu \mathrm{m}$ opening at the tip, was filled with rhodamine dextran amine (RDA, MW $=3,000$, Molecular Probes, Inc., Eugene, OR, USA) made at $6.25 \%$ with a $0.4 \%$ Triton $\mathrm{X}-100$ in PBS, and attached by fine tubing to a Picospritzer. Using several pulses ranging from 10 to $50 \mathrm{~ms}$ at $20 \mathrm{psi}$, RDA was pressure injected into the dorsal midline of the medulla at the floor of the fourth ventricle to label only contralateral-projecting $\mathrm{NM}$ axons, as described previously [17]. The tissue was immersed in aCSF continuously infused with $95 \% \mathrm{O}_{2} / 5 \%$ $\mathrm{CO}_{2}$ for 15 minutes. The tissue was then prepared for histologic sectioning as described in the next section and the axon tracings were later visualized by fluorescent microscopy.

\section{Histology}

Tissue was fixed in $4 \%$ paraformaldehyde (PFA) in PBS for at least 2 hours, and then washed in 1X PBS for 10 minutes. For Vibratome sectioning, tissue was embedded in 2\% low-melting agar (Fisher Scientific, Pittsburgh, PA, USA) and mounted to the stage, fully immersed in $1 \mathrm{X}$ PBS during sectioning. For cryostat sectioning, tissue was cryoprotected in $30 \%$ sucrose overnight prior to embedding in OCT medium. For all tissues, sequential 50 $\mu \mathrm{m}$ sections in the coronal plane were collected on a subbed glass slide and dried on a slide warmer at $37^{\circ} \mathrm{C}$. 
Most sections were counterstained with the nuclear stain bisbenzimide $(2 \mu \mathrm{g} / \mathrm{mL}$ in PBS, five minutes incubation followed by five minutes $1 \mathrm{X}$ PBS wash) to facilitate identification of NM and NL. Slides were coverslipped with Glycergel mounting medium (Dako, Carpinteria, CA, USA) and stored in the dark at $4^{\circ} \mathrm{C}$ until analyzed. A separate group of samples underwent immunofluorescence staining to confirm plasmid expression or fusion protein location. These samples were sectioned on the cryostat as described above into $25 \mu \mathrm{m}$ sections.

\section{Immunofluorescence}

Immunostaining was performed on a subset of samples to confirm plasmid expression with anti-EphB2 primary antibody or to confirm fusion protein localization with anti-Fc secondary antibody. Briefly, a hydrophobic pappen border was drawn around the sections and the slides were rinsed then incubated in blocking solution (4\% goat serum, $0.01 \%$ Triton in $1 \mathrm{X}$ PBS) for one hour at room temperature in a humid chamber. The slides were quickly rinsed with PBS and then incubated with the primary antibody for confirmation of plasmid expression, or with secondary antibody for visualization of fusion protein localization. For slides undergoing primary antibody labeling, slides were rinsed after one day then incubated with the secondary antibody for labeling. All secondary antibody labeling was performed with Alexa Fluor anti-Fc antibodies (Molecular Probes, Inc., Eugene, OR, USA) used at a 1:1,000 dilution in blocking solution and incubated for two hours at room temperature in the dark.

\section{Image and data analysis}

Experimental embryos with no gross abnormalities were used at E10 for data collection. Criteria for inclusion in further analysis were EGFP expression in the auditory brainstem of transfected embryos, four days of successful hindbrain injections for ex ovo cultured embryos, and successful midline axon tracing. Samples were coded and analyzed blind to experimental conditions. The slides were viewed on a Zeiss AxioSkop-2 epifluorescence microscope (Carl Zeiss, Thornwood, NY, USA) using 10X, 20X or $40 \mathrm{X}$ objective lenses. To quantify NM-NL axon targeting errors, NL was viewed at 20 and 40X across several focal planes in order to allow for systematic analysis of the entire width of every section. Targeting errors were defined as axons arising from contralateral NM that crossed the NL cell body layer to terminate in the dorsal neuropil, visible as a cell-free layer with bisbenzimide staining and dorsal to NL somata. At this age in development, NL was typically visible across at least eight sections, or $400 \mu \mathrm{m}$ of coronally sectioned brain. Since the central region of this extent is where NL presents robustly as a single layer of cells (assuming no anatomical variation exists), this is the area where targeting errors can be most accurately quantified. Thus, for each embryo, $n=1$ and a total of $400 \mu \mathrm{m}$ of NL extent was analyzed, typically $200 \mu \mathrm{m}$ (four adjacent sections X $50 \mu \mathrm{m}$ each) from each left and right sides of the brain, at the central region along the NL axes. Mediolateral lengths were measured with Openlab software (Perkin Elmer, Waltham, MA, USA) by recording the distance between the medial-most and lateral-most borders of identifiable NL soma in equivalent sections. Rostrocaudal lengths were measured by counting the number of adjacent sections containing NL soma and multiplying by 50 (the thickness of each section). Left and right sides were recorded separately for anatomical measures. Once data collection was complete, the samples were decoded and grouped for comparison of means. Representative images were taken with Zeiss Axiocam digital camera and Openlab software. Any additional image analysis, tiling and color rendering or color merging was performed with Adobe Photoshop (Adobe, San Jose, CA, USA) and figures were prepared with Adobe Illustrator. All statistical analyses were done with JMP software (JMP, Cary, NC, USA) using a Student's $t$-test and a significance value of $P<0.05$.

\section{Abbreviations}

ED: Embryonic day; ILDs: Interaural level differences; ITDs: Interaural time differences; NL: Nucleus laminaris; NM: Nucleus magnocellularis; PBS: Phosphate buffered saline; PFA: Paraformaldehyde.

\section{Competing interests}

The authors declare that they have no competing interests.

\section{Authors' contributions}

MRA carried out the experiments and analysis for the electroporation and fusion protein studies. MRA and KSC contributed to the experimental design and manuscript preparation. Both authors have read and approved the final manuscript.

\section{Acknowledgments}

The authors wish to thank Drs. Candace Hsieh, Matt Korn and Paul Nakamura for their expertise and invaluable feedback regarding experimentation and manuscript preparation, and Scott Koppel, Punit Patel, Tiffanie Rehaume, and Michelle Tjia for technical assistance. This work was supported by NSF IOB-0642346, NIH T32-DC010775-01, NIH T32-GM008620-13, and P30 DC008369.

Received: 1 May 2012 Accepted: 26 July 2012

Published: 21 August 2012

\section{References}

1. Molea D, Rubel EW: Timing and topography of nucleus magnocellularis innervation by the cochlear ganglion. J Comp Neurol 2003, 466:577-591.

2. Rubel EW, Fritzsch B: Auditory system development: primary auditory neurons and their targets. Annu Rev Neurosci 2002, 25:51-101.

3. Rubel EW, Smith DJ, Miller LC: Organization and development of brain stem auditory nuclei of the chicken: ontogeny of $n$. magnocellularis and n. laminaris. J Comp Neurol 1976, 166:469-489.

4. Joseph AW, Hyson RL: Coincidence detection by binaural neurons in the chick brain stem. J Neurophysiol 1993, 69:1197-1211.

5. Boord RL: Ascending projections of the primary cochlear nuclei and nucleus laminaris in the pigeon. J Comp Neurol 1968, 133:523-541. 
6. Parks TN, Rubel EW: Organization and development of the brain stem auditory nuclei of the chicken: primary afferent projections. J Comp Neurol 1978, 180:439-448.

7. Pettigrew AG, Ansselin AD, Bramley JR: Development of functional innervation in the second and third order auditory nuclei of the chick. Development 1988, 104:575-588.

8. Overholt EM, Rubel EW, Hyson RL: A circuit for coding interaural time differences in the chick brainstem. J Neurosci 1992, 12:1698-1708.

9. Hyson RL: The analysis of interaural time differences in the chick brain stem. Physiol Behav 2005, 86:297-305.

10. Hackett JT, Jackson H, Rubel EW: Synaptic excitation of the second and third order auditory neurons in the avian brain stem. Neuroscience 1982, 7:1455-1469.

11. Young SR, Rubel EW: Frequency-specific projections of individual neurons in chick brainstem auditory nuclei. J Neurosci 1983, 3:1373-1378.

12. Seidl $A H$, Rubel EW, Harris DM: Mechanisms for adjusting interaural time differences to achieve binaural coincidence detection. J Neurosci 2010, 30:70-80.

13. Cramer KS, Cerretti DP, Siddiqui SA: EphB2 regulates axonal growth the midline in the developing auditory brainstem. Dev Biol 2006, 295:76-89.

14. Young SR, Rubel EW: Embryogenesis of arborization pattern and topography of individual axons in N. laminaris of the chicken brain stem. J Comp Neurol 1986, 254:425-459.

15. Hendricks SJ, Rubel EW, Nishi R: Formation of the avian nucleus magnocellularis from the auditory anlage. J Comp Neurol 2006, 498:433-442.

16. Lippe WR: Rhythmic spontaneous activity in the developing avian auditory system. J Neurosci 1994, 14:1486-1495.

17. Cramer KS, Bermingham-McDonogh O, Krull CE, Rubel EW: EphA4 signaling promotes axon segregation in the developing auditory system. Dev Biol 2004, 269:26-35

18. Jhaveri S, Morest DK: Neuronal architecture in nucleus magnocellularis of the chicken auditory system with observations on nucleus laminaris: a light and electron microscope study. Neuroscience 1982, 7:809-836.

19. Cheng HJ, Nakamoto $M$, Bergemann AD, Flanagan JG: Complementary gradients in expression and binding of ELF-1 and Mek4 in development of the topographic retinotectal projection map. Cell 1995, 82:371-381.

20. Drescher U, Kremoser C, Handwerker C, Loschinger J, Noda M, Bonhoeffer F: In vitro guidance of retinal ganglion cell axons by RAGS, a $25 \mathrm{kDa}$ tectal protein related to ligands for Eph receptor tyrosine kinases. Cell 1995, 82:359-370.

21. Reber $M$, Hindges $R$, Lemke $G$ : Eph receptors and ephrin ligands in axon guidance. Adv Exp Med Biol 2007, 621:32-49.

22. Mann F, Ray S, Harris W, Holt C: Topographic mapping in dorsoventral axis of the Xenopus retinotectal system depends on signaling through ephrin-B ligands. Neuron 2002, 35:461-473.

23. Dottori M, Hartley L, Galea M, Paxinos G, Polizzotto M, Kilpatrick T, Bartlett PF, Murphy M, Kontgen F, Boyd AW: EphA4 (Sek1) receptor tyrosine kinase is required for the development of the corticospinal tract. Proc Natl Acad Sci U S A 1998, 95:13248-13253.

24. Kullander K, Croll SD, Zimmer M, Pan L, McClain J, Hughes V, Zabski S, DeChiara TM, Klein R, Yancopoulos GD, Gale NW: Ephrin-B3 is the midline barrier that prevents corticospinal tract axons from recrossing, allowing for unilateral motor control. Genes Dev 2001, 15:877-888.

25. Williams SE, Mann F, Erskine L, Sakurai T, Wei S, Rossi DJ, Gale NW, Holt CE, Mason CA, Henkemeyer M: Ephrin-B2 and EphB1 mediate retinal axon divergence at the optic chiasm. Neuron 2003, 39:919-935.

26. Cramer KS: Eph proteins and the assembly of auditory circuits. Hear Res 2005, 206:42-51.

27. Cramer KS, Karam SD, Bothwell M, Cerretti DP, Pasquale EB, Rubel EW: Expression of EphB receptors and EphrinB ligands in the developing chick auditory brainstem. J Comp Neurol 2002, 452:51-64.

28. Person AL, Cerretti DP, Pasquale EB, Rubel EW, Cramer KS: Tonotopic gradients of Eph family proteins in the chick nucleus laminaris during synaptogenesis. J Neurobiol 2004, 60:28-39.

29. Gale NW, Holland SJ, Valenzuela DM, Flenniken A, Pan L, Ryan TE, Henkemeyer M, Strebhardt K, Hirai H, Wilkinson DG, Pawson T, Davis S, Yancopoulos GD: Eph receptors and ligands comprise two major specificity subclasses and are reciprocally compartmentalized during embryogenesis. Neuron 1996, 17:9-19.
30. Pasquale EB: Eph-ephrin bidirectional signaling in physiology and disease. Cell 2008, 133:38-52.

31. Singla N, Goldgur Y, Xu K, Paavilainen S, Nikolov DB, Himanen JP: Crysta structure of the ligand-binding domain of the promiscuous EphA4 receptor reveals two distinct conformations. Biochem Biophys Res Commun 2010, 399:555-559.

32. Himanen JP, Chumley MJ, Lackmann M, Li C, Barton WA, Jeffrey PD, Vearing C, Geleick D, Feldheim DA, Boyd AW, Henkemeyer M, Nikolov DB: Repelling class discrimination: ephrin-A5 binds to and activates EphB2 receptor signaling. Nat Neurosci 2004, 7:501-509.

33. Holland SJ, Gale NW, Mbamalu G, Yancopoulos GD, Henkemeyer M, Pawson $\mathrm{T}$ : Bidirectional signalling through the EPH-family receptor Nuk and its transmembrane ligands. Nature 1996, 383:722-725.

34. Mellitzer $\mathrm{G}, \mathrm{Xu} \mathrm{Q}$, Wilkinson DG: Control of cell behaviour by signalling through Eph receptors and ephrins. Curr Opin Neurobio/ 2000, 10:400-408.

35. Murai KK, Pasquale EB: 'Eph'ective signaling: forward, reverse and crosstalk. J Cell Sci 2003, 116:2823-2832

36. Zhou CQ, Lee J, Henkemeyer MJ, Lee KH: Disruption of ephrin-B/EphB interaction results in abnormal cochlear innervation patterns. Laryngoscope 2011, 121:1541-1547.

37. Howard MA, Rodenas-Ruano A, Henkemeyer M, Martin GK, Lonsbury-Martin BL, Liebl DJ: Eph receptor deficiencies lead to altered cochlear function. Hear Res 2003, 178:118-130.

38. Hsieh CY, Hong CT, Cramer KS: Deletion of EphA4 enhances deafferentation-induced ipsilateral sprouting in auditory brainstem projections. J Comp Neurol 2007, 504:508-518.

39. Huffman KJ, Cramer KS: EphA4 misexpression alters tonotopic projections in the auditory brainstem. Dev Neurobiol 2007, 67:1655-1668.

40. Hsieh CY, Nakamura PA, Luk SO, Miko IJ, Henkemeyer M, Cramer KS: Ephrin$B$ reverse signaling is required for formation of strictly contralateral auditory brainstem pathways. J Neurosci 2010, 30:9840-9849.

41. Nakamura PA, Hsieh CY, Cramer KS: EphB signaling regulates target innervation in the developing and deafferented auditory brainstem. Dev Neurobiol 2012, 72:1243-1255.

42. Miko IJ, Henkemeyer M, Cramer KS: Auditory brainstem responses are impaired in EphA4 and ephrin-B2 deficient mice. Hear Res 2008 235:39-46.

43. Coate TM, Raft S, Zhao X, Ryan AK, Crenshaw EB 3rd, Kelley MW: Otic mesenchyme cells regulate spiral ganglion axon fasciculation through a Pou3f4/EphA4 signaling pathway. Neuron 2012, 73:49-63.

44. Cramer KS, Rosenberger MH, Frost DM, Cochran SL, Pasquale EB, Rubel EW Developmental regulation of EphA4 expression in the chick auditory brainstem. J Comp Neurol 2000, 426:270-278.

45. Siddiqui SA, Cramer KS: Differential expression of Eph receptors and ephrins in the cochlear ganglion and eighth cranial nerve of the chick embryo. J Comp Neurol 2005, 482:309-319.

46. Cramer KS, Fraser SE, Rubel EW: Embryonic origins of auditory brain-stem nuclei in the chick hindbrain. Dev Biol 2000, 224:138-151.

47. Ethell IM, Irie F, Kalo MS, Couchman JR, Pasquale EB, Yamaguchi Y: EphB/ syndecan-2 signaling in dendritic spine morphogenesis. Neuron 2001, 31:1001-1013.

48. Hruska M, Dalva MB: Ephrin regulation of synapse formation, function and plasticity. Mol Cell Neurosci 2012, 50:35-44.

49. Akaneya Y, Sohya K, Kitamura A, Kimura F, Washburn C, Zhou R, Ninan I, Tsumoto T, Ziff EB: Ephrin-A5 and EphA5 interaction induces synaptogenesis during early hippocampal development. PLoS One 2010, 5:e12486.

50. Li W, Zheng Z, Keifer J: Transsynaptic EphB/Ephrin-B signaling regulates growth of presynaptic boutons required for classical conditioning. J Neurosci 2011, 31:8441-8449.

51. McClelland AC, Hruska M, Coenen AJ, Henkemeyer M, Dalva MB: Trans-synaptic EphB2-ephrin-B3 interaction regulates excitatory synapse density by inhibition of postsynaptic MAPK signaling. Proc Natl Acad SCi U S A 2010, 107:8830-8835.

52. McClelland AC, Sheffler-Collins SI, Kayser MS, Dalva MB: Ephrin-B1 and ephrin-B2 mediate EphB-dependent presynaptic development via syntenin-1. Proc Natl Acad Sci U S A 2009, 106:20487-20492.

53. Klein R: Bidirectional modulation of synaptic functions by Eph/ephrin signaling. Nat Neurosci 2009, 12:15-20. 
54. Lim BK, Matsuda N, Poo MM: Ephrin-B reverse signaling promotes structural and functional synaptic maturation in vivo. Nat Neurosci 2008, 11:160-169.

55. Dalva MB, Takasu MA, Lin MZ, Shamah SM, Hu L, Gale NW, Greenberg ME: EphB receptors interact with NMDA receptors and regulate excitatory synapse formation. Cell 2000, 103:945-956.

56. Lai KO, Ip NY: Synapse development and plasticity: roles of ephrin/Eph receptor signaling. Curr Opin Neurobiol 2009, 19:275-283.

57. Kayser MS, McClelland AC, Hughes EG, Dalva MB: Intracellular and transsynaptic regulation of glutamatergic synaptogenesis by EphB receptors. J Neurosci 2006, 26:12152-12164.

58. Kayser MS, Nolt MJ, Dalva MB: EphB receptors couple dendritic filopodia motility to synapse formation. Neuron 2008, 59:56-69.

59. Xu NJ, Sun S, Gibson JR, Henkemeyer M: A dual shaping mechanism for postsynaptic ephrin-B3 as a receptor that sculpts dendrites and synapses. Nat Neurosci 2011, 14:1421-1429.

60. Sloniowski S, Ethell IM: Looking forward to EphB signaling in synapses. Semin Cell Dev Biol 2012, 23:75-82.

61. Xu NJ, Henkemeyer M: Ephrin reverse signaling in axon guidance and synaptogenesis. Semin Cell Dev Biol 2012, 23:58-64.

62. Yin Y, Yamashita Y, Noda H, Okafuji T, Go MJ, Tanaka H: EphA receptor tyrosine kinases interact with co-expressed ephrin-A ligands in cis. Neurosci Res 2004, 48:285-296.

63. Carvalho RF, Beutler M, Marler KJ, Knoll B, Becker-Barroso E, Heintzmann R, $\mathrm{Ng} \mathrm{T}$, Drescher U: Silencing of EphA3 through a cis interaction with ephrinA5. Nat Neurosci 2006, 9:322-330.

64. Egea J, Klein R: Bidirectional Eph-ephrin signaling during axon guidance. Trends Cell Biol 2007, 17:230-238.

65. Marquardt T, Shirasaki R, Ghosh S, Andrews SE, Carter N, Hunter T, Pfaff SL: Coexpressed EphA receptors and ephrin-A ligands mediate opposing actions on growth cone navigation from distinct membrane domains Cell 2005, 121:127-139.

66. Kao TJ, Kania A: Ephrin-mediated cis-attenuation of Eph receptor signaling is essential for spinal motor axon guidance. Neuron 2011, 71:76-91.

67. Hattori M, Osterfield M, Flanagan JG: Regulated cleavage of a contact-mediated axon repellent. Science 2000, 289:1360-1365.

68. Hindges R, McLaughlin T, Genoud N, Henkemeyer M, O'Leary DD: EphB forward signaling controls directional branch extension and arborization required for dorsal-ventral retinotopic mapping. Neuron 2002, 35:475-487.

69. Mann F, Harris WA, Holt CE: New views on retinal axon development: a navigation guide. Int J Dev Biol 2004, 48:957-964.

70. McLaughlin T, Hindges R, Yates PA, O'Leary DD: Bifunctional action of ephrin-B1 as a repellent and attractant to control bidirectional branch extension in dorsal-ventral retinotopic mapping. Development 2003, 130:2407-2418.

71. Nakagawa S, Brennan C, Johnson KG, Shewan D, Harris WA, Holt CE: Ephrin-B regulates the Ipsilateral routing of retinal axons at the optic chiasm. Neuron 2000, 25:599-610.

72. Gebhardt C, Bastmeyer M, Weth F: Balancing of ephrin/Eph forward and reverse signaling as the driving force of adaptive topographic mapping. Development 2012, 139:335-345.

73. Senturk A, Pfennig S, Weiss A, Burk K, Acker-Palmer A: Ephrin Bs are essential components of the Reelin pathway to regulate neuronal migration. Nature 2011, 472:356-360.

74. Santiago A, Erickson CA: Ephrin-B ligands play a dual role in the control of neural crest cell migration. Development 2002, 129:3621-3632.

75. Smith A, Robinson V, Patel K, Wilkinson DG: The EphA4 and EphB1 receptor tyrosine kinases and ephrin-B2 ligand regulate targeted migration of branchial neural crest cells. Curr Biol 1997, 7:561-570.

76. Krull CE, Lansford R, Gale NW, Collazo A, Marcelle C, Yancopoulos GD, Fraser SE, Bronner-Fraser M: Interactions of Eph-related receptors and ligands confer rostrocaudal pattern to trunk neural crest migration. Curr Biol 1997, 7:571-580

77. Chan J, Mably JD, Serluca FC, Chen JN, Goldstein NB, Thomas MC, Cleary JA, Brennan C, Fishman MC, Roberts TM: Morphogenesis of prechordal plate and notochord requires intact Eph/ephrin B signaling. Dev Biol 2001, 234:470-482.

78. Kemp HA, Cooke JE, Moens CB: EphA4 and EfnB2a maintain rhombomere coherence by independently regulating intercalation of progenitor cells in the zebrafish neural keel. Dev Biol 2009, 327:313-326.
79. Cooke JE, Moens CB: Boundary formation in the hindbrain: Eph only it were simple. Trends Neurosci 2002, 25:260-267.

80. Rodger J, Salvatore L, Migani P: Should I stay or should I go? Ephs and Ephrins in neuronal migration. Neurosignals 2012, 20:190-201.

81. Catchpole T, Henkemeyer M: EphB2 tyrosine kinase-dependent forward signaling in migration of neuronal progenitors that populate and form a distinct region of the dentate niche. J Neurosci 2011, 31:11472-11483.

82. Davy A, Soriano P: Ephrin signaling in vivo: look both ways. Dev Dyn 2005, 232:1-10.

doi:10.1186/1749-8104-7-29

Cite this article as: Allen-Sharpley and Cramer: Coordinated Eph-ephrin signaling guides migration and axon targeting in the avian auditory system. Neural Development 2012 7:29.

\section{Submit your next manuscript to BioMed Central and take full advantage of:}

- Convenient online submission

- Thorough peer review

- No space constraints or color figure charges

- Immediate publication on acceptance

- Inclusion in PubMed, CAS, Scopus and Google Scholar

- Research which is freely available for redistribution

Submit your manuscript at www.biomedcentral.com/submit
C BioMed Central 